\title{
Pedagogic position of resident physicians as a factor contributing to forming a healthy-oriented lifestyle in patients
}

\author{
Nina Pavlovna Vanchakova ${ }^{1}$, Andrey Anatoljevich Bogatyrev ${ }^{1}$, Veronica Aleksandrovna \\ Denishenko ${ }^{1}$, Natalia Valerjevna Krasilnikova ${ }^{1}$, Anton Mikhailovitch Shaporov ${ }^{1}$, and \\ Elizaveta Aleksandrovna Vatskel $^{1}$ \\ ${ }^{1}$ Pavlov First Saint Petersburg State Medical University, Chair of Pedagogy and Psychology, \\ Postgraduate Education Faculty,1197022,Saint Petersburg, Russia
}

\begin{abstract}
The paper describes the features and components of the academic course content and teaching techniques aimed at forming the pedagogic position (a set of pedagogical knowledges, skills, competences, values, and attitudes) of a doctor in young resident physicians. This position contributes to an effective health-oriented lifestyle dissemination and adoption, especially in patients with chronic diseases. It reflects a new perception of physician's vocational duties, including care for patients' life and their need for psychological support. Biopsychosocial approach to health and disease was chosen as a conceptual core of the academic course content and methodology design, specially elaborated to unite pedagogical aspects of the physician's job with the clinical ones. The set of methods aimed at doctor's pedagogical position formation and development of professional reflection, values and attitudes included lecturing, interviewing, case studies and clinical cases analysis, discussion, questionnaires, brainstorming, trainings and testing. Eighty-six resident physicians were observed within this study. Such components of the pedagogic position as knowledges, skills, attitudes and motivation showed more dynamics, whereas personal traits were seen as a more static and stable component of the pedagogic position in resident physicians. A remarkable divergence of progress was elicited between doctors of various specialties.
\end{abstract}

\section{Introduction}

Nowadays humanity has faced changes in the rhythm and way of life, the ecological situation, and other disturbing factors. Unhealthy diet, in sufficient physical activity, various addictions, and things that jeopardize one's health lead to worsening of the health of the people. These facts make the task of formation of a healthy lifestyle sets and appropriate health-oriented behavior habit crucial for society and life quality. Many people nowadays face the challenge of chronic diseases, and so they cannot keep the casual lifestyle they kept to before certain health problems appeared. These physically challenged people need special education to study how to live with the disease. Patient education is a recently popular concept, and it is viewed as an underestimated tool that contributes to 
health literacy, health promotion, ill-health prevention, and acquisition of a new lifestyle under conditions of the disease. It can function as one of the key tools of disease prevention as well.

The world experience of healthcare shows that education of patients with chronic diseases aimed at changing forms of behavior and lifestyle has a positive effect on patients' condition, general level of well-being and the dynamics of the treatment, and it helps to reduce mortality from chronic diseases [1]. Based on the currently accepted biopsychosocial paradigm of health [2], it is now believed that treatment and rehabilitation of chronically ill people imply treating not only the disease itself but also helping the patient to adjust to life within frame of the new conditions of the disease, providing educational, psychological, and social support. These tasks can be solved within a developed system of psychological and educational support of patients, in particular, patient education.

Patient education mission can be provided by a healthcare professional (physicians and nurses) who have received vocational training in this sphere. Nowadays patient education is declared as one of the Russian medical education development priority trends, and it finds place in the modern curriculum of both physicians and nurses. Within Russian healthcare model doctors are seen as the specialists who can form a healthy lifestyle in patients, their kin, general public [3] Young physicians who come into medical residency should receive special training in the sphere of patient education, and formation of health-oriented lifestyle in patients, and healthy lifestyle among people.

\section{Literature review}

There exist several points of view on the concept of "lifestyle" (life style, life-style). First implemented by A. Adler, this term has received many interpretations due to various research approaches (Weberian, psychological, market research, gender, and many others) [4]. From the medical point of view "lifestyle" can be referred to as a way of living of certain people, social groups, or nations that is pre-determined by certain geographical, economic, political, cultural, and religious factors. It includes routine behavior, life habits and everyday risks and actions (like food, physical activities, job duties, health hazards, etc. [5] It involves behavior, attitudes, habits the person experiences in everyday life influencing one's health [6]. A healthy lifestyle means the ability to control one's behaviors that have an effect on one's health as well as choosing proper activities within everyday life. [7].

Today there exist studies dedicated to educational aspects of a healthy lifestyle. Scientific researchers study its formation in children and students of various age [8-11], cases of occupational lifestyle diseases and hazards [12, 13]. Medical aspects of a healthy lifestyle are studied within the prism of its influence on patient's health [14], disease prevention, reduction in mortality and risks of relapses, and so on [15-17].

However, people face certain health problems, including diseases, in some cases chronic. These can decrease the quality of life, lead to a reduction of everyday activity and functioning, and cause many other somatic, psychological, social, financial, and associated problems in the individual's life [18]. At the same time having experienced a certain disease or health problem, an individual can try to maintain one's health on the most appropriate level possible under the circumstances. Therefore, we claim that a conception of the health-oriented lifestyle of patients should be used in these cases. It implies behavior and activities that allow an individual to retain one's health status on a maximum possible level for that particular person [19]. Health-oriented lifestyle and behavior in patients can be formed within pedagogical scope of daily vocational activities implemented by healthcare practitioners. It can include the following directions: commitment to a health- 
oriented lifestyle; raising the patient's awareness of the disease and what affects it; raising adherence and motivation for treatment and rehabilitation; developing skills of behavior within treatment or rehabilitation, skills in using medical equipment necessary to monitor and support one's health status; skills in self-hygiene in the conditions of the disease, providing psychological support if needed, etc.

We can't but mention that sometimes those who have faced some serious problem with health may try to return to the lifestyle they used to keep before the problem has arisen, sometimes asking the doctor "to return the previous level of health", "the condition that was before" that in most cases is impossible. In these cases, healthcare workers can orient the patient at reaching a health-oriented lifestyle that will be suitable for one's health condition. Such type of lifestyle in our opinion means that one should try to keep the most appropriate behavior for certain health problems tending to keep the highest level of health possible in a certain situation (taking into account chronic diseases, individual health status, needs, abilities, etc.). Patient education for people with various diseases is oriented at training and educating the patient to form a new lifestyle focused on raising the patient's life expectancy and improving the quality of life taking into account the consequences of the disease.

In the Russian healthcare education system, these activities are reflected in Federal State Educational Standards for Higher Education. Physicians' employment duties include promoting a healthy lifestyle, providing health literacy, forming a special health-oriented lifestyle in patients who experience treatment [3]. Physicians are also in charge of informing patients and their kin (if needed), providing effective communication, providing psychological and pedagogical support in the conditions of treatment and rehabilitation. Many of studies in Russia are dedicated to pedagogic and educational competencies and activities the healthcare workers should acquire [20, 21, 22]. They focus mostly on the essence and peculiarities of pedagogic and psychological activities of a physician, the knowledge and competencies specialists need, as well as the educational models that can form it. However, the practice shows that sometimes it is hard for a physician, especially a young one, to identify these activities as one of the physician's professional tasks as they are more concentrated on matters of diagnostics and treatment. We believe that attention should be paid to the attitudes of doctors to educational activities and certain educational work should be organized for young doctors to make it their inner attitude.

A series of studies conducted at Pavlov First Saint Petersburg Medical University introduce the notion of the pedagogical position of a doctor. It can be described as a system of the physician's attitudes to the pedagogical aspects of one's professional activity, expressed in the awareness of the importance of pedagogical interaction with patients, forming health-oriented lifestyle, pedagogic interaction with patient's kin (if needed), as well as the intention, the willingness to implement pedagogical interaction with patients, implying special theoretical basis and expressed in deliberate effective pedagogical activity-based acquired practical skills. The pedagogical position of a physician can be formulated as a kind of an attitude when the physician sees oneself not only as a doctor but also as an educator who implements pedagogical duties forming a health-oriented lifestyle and helping to adjust to a new lifestyle within treatment or rehabilitation. The pedagogical position of the physician contains several components: knowledges, skills, values, motivation, patient and job attitudes, reflective component, and personal traits (empathy, tolerance, reflectivity, etc). Thus, it can be understood as a complex, integrative professional competency that focuses primarily on specialist's attitudes, beliefs, and senseof-self [23, 24]. 


\section{Research methods and methodology}

The current research was aimed at studying the pedagogical position of the resident physician - a young physician who is just entering the professional field. The following method of its assessment was used. It comprises such components as a) knowledges, b) motivation, values and attitudes c) skills, d) professional reflection, and e) personal traits that contribute to effective patient education were seen as the criteria of assessment of the pedagogical position. To make a quantitative assessment of a pedagogical position, the following calculation procedure was performed: each criterion (a component of the pedagogical position) was assigned a certain score: a high level of formation of a certain component was 3 points, an average was 2 points, a low one was 1 point. Thus, a minimum of points a resident physician could get for each of the components (taking into account five components-structure of pedagogical position) was 5 points, the maximum is 15 points. The total value was defined by calculating the arithmetic mean. Quantification of the level of formation of a pedagogical position was conducted the following way. The low level of pedagogic position corresponded with values of 1-1.6 scores. The mean level of pedagogic position development corresponded values of 1.7-2.3 scores. The high level of pedagogic position development corresponded with values of 2.4-3 scores.

The cognitive component was assessed by using special training thesauri the resident physicians had to fulfill at the beginning of the course and the end of the course. Various terms and concepts concerning health-oriented lifestyle formation and patient education were to be interpreted and explained by the students. The dynamics in knowledges before and after the course was assessed this way. The skills were assessed when the resident physicians were making the educational design for patient education schools, drafts for the aimed at health-oriented lifestyle forming. The motivation and values component were assessed by questionnaire aimed at studying the willingness to perform health-oriented education for patients and the general public. The reflexive component was assessed with a complex of measurement tools, such as writing an essay (about the routine professional tasks and its educational, psychological, communicative dimensions), interviewing physicians on the educational and lifestyle aspects of doctor-to-patient job communication, and so on. Personal traits, contributing to effective patient education, were studied with the help of the Questionnaire of Emotional Empathy Measurements (Mehrabyan \& Epstein) [25] and the Reflexivity Questionnaire by A.V. Karpov [26]. Eighty-six first-year resident physicians (therapeutic and surgical specialties) took part in the research $(n=86)$.

\section{Results}

Several assessments were made (beginning-of-the-course and the end-of-the-course assessment). The results of the first assessment (based on questionnaire and knowledges tenting) showed that the components of the pedagogical position of resident physicians were not high, 23 percent showed mean levels of pedagogical position (mostly due to high levels of personal traits like empathy and understanding pedagogical dimensions of profession due to the experience obtained in the clinic). The majority of resident physicians who took part in the experiment showed initially a low level of pedagogical position development (76 percent).

After the first assessment, the resident physicians were offered the educational course. The content of the program contained the questions of patient education, health-oriented lifestyle formation, communication between physicians and patients, questions of pedagogical design (for planning for patient education). The biopsychosocial approach was seen as the core element of introducing pedagogy into the sight of young doctors helping to interconnect the matters of patient education with the professional belief system of resident 
physicians. The learner-centered education approach was widely used. The problemsolving tasks were designed the way they could appeal to one's individual experience the resident physician had. The overall activity approach was aimed at maintaining the involvement of the students in practical activity. It led to the acquisition of certain experience within learning activities. For example, one of the practical tasks was designing certain patients' schools and certain patient education episodes (from the standpoint of the pedagogical design, not mere clinical content).

A number of educational tasks were aimed at the formation of professional reflection (writing essays on educational aspects of one's profession, analyzing routine professional duties to find there the pedagogical dimension, analyzing education standards for a certain specialty, etc). Clinical problem solving, where the core of the problem contained educational, psychological challenges were used. The case study was also one of the methods, where various clinical-oriented cases were used and the task was to make the analyses of the problem taking into account a wide range of pedagogical, psychological, social aspects that contribute to patient education and healthy lifestyle forming. Communication aspects, analyzing verbal and non-verbal matters of doctor-to-patient communication were as well covered within case-studies and clinical problem-solving technology.

By the end of the course, learners' preparedness reassessment was made. The results of the re-assessment showed a significant increase in components of the pedagogical position development.

Table 1. Number of resident physicians with different levels of formation of a pedagogical position.

\begin{tabular}{|c|c|c|c|c|}
\hline & \multicolumn{2}{|c|}{ Before } & \multicolumn{2}{c|}{ After } \\
\hline & Amount & $\%$ & Amount & $\%$ \\
\hline High level & 0 & 0 & 31 & 36 \\
\hline Mean level & 20 & 23 & 42 & 48 \\
\hline Low level & 66 & 76 & 15 & 17 \\
\hline
\end{tabular}

\section{Discussion}

One of the challenges the resident physicians encountered was the difficulty of perceiving a situation of patient education from the pedagogical point of view. For example, when the resident physicians were making the lessons within the patient education they were mostly concentrating upon clinical matters (the content of the lesson included medical information), forgetting about pedagogic rules, setting educational goals, proper timing, making a lesson plan, etc. Thus one of the key targets of the course was to teach the resident physicians to perceive patient education from the standpoint of pedagogy, not only their medical specialty. We believe that it can contribute to better providing patient education and health-oriented behavior forming as the physician who understands basic pedagogy aspects can make the education activities consistent with patient's perception.

Analysis of the data received led us to an interesting observation. There was found a remarkable knowledges shift and positive development of the level of perception of patient education in therapeutic and surgical specialties. Resident physicians acquiring so-called therapeutic specialties, such as endocrinologists, cardiologists, gastroenterologists demonstrated a more profound understanding of a patient education as one of the inherent professional tasks in a much higher percentage ( $81 \%, 35$ out of 43 resident physicians) in comparison to surgical specialties (surgeons, cardiovascular surgeons, trauma surgeons, etc), $21 \%$ - 9 out of 43 resident physicians. This can at least be partly accounted for the primary experience in the clinic the resident physicians had received by the time when the pilot experiment pedagogy course started and the characteristics of one's specialty. In case 
the resident physicians have already got into the clinical settings and special patient education schools they, of course, received comprehension of pedagogic dimensions of their work. However, there still were some resident physicians of therapeutic specialties who didn't see any pedagogical (educational) dimension in their work (which might be accounted for the lack or scarcity of clinical job experience they had). Another possible reasoning for that advancement divergence gap between different specialties is that students who choose therapeutic specialties are usually more oriented at interacting with patients. i.e. communicating, educating, due to early development of certain vocationally important personality traits. This can become the topic of further investigations and we do hope to continue it. However, the first comparison we made showed that there existed a certain difference in levels of such traits as reflexivity and empathy between therapeutic and surgical specialties.

Table 2. Mean values for Empathy and Reflexivity in therapeutic and surgical specialties.

\begin{tabular}{|c|c|c|c|}
\hline & Surgical specialties $(\mathbf{n}=\mathbf{4 3})$ & Therapeutic specialties $(\mathbf{n}=\mathbf{4 3})$ & $\mathbf{p}$ \\
\hline Empathy & $59.97 \pm 4.58$ & $66.9 \pm 6.18$ & $<0,001$ \\
\hline Reflexivity & $130.27 \pm 12.38$ & $144.58 \pm 18.67$ & $<0,001$ \\
\hline
\end{tabular}

It should be noted that for doctors, especially for the young ones, pedagogical issues may seem to be "distant", "incomprehensible", "somewhat alien", since vocational activities must have been primarily associated with clinically oriented activities (diagnostics, treatment, therapy, surgical interventions, various medical procedures, etc.). Such rendering of the profession by a young resident physician is facilitated by the predominance of natural science and biomedical disciplines in the pregraduate curriculum, and the entering process into clinical practice (when a young doctor is focused on acquiring "most precious clinical experience"). Thus special educational efforts should be made to introduce medical students and resident physicians to the issues of healthy lifestyle formation and patient education.

The amount of psychological and pedagogical disciplines is not that high in the medical education curriculum in comparison to clinical and naturalist disciplines. The reason is that the natural sciences and professional clinical training take the leading role. In the system of postgraduate education, psychological and educational training somewhat expands. Thus. for organizing a Pedagogy course there is a strong need for integrate paradigm approach specially designed to unite in harmony hard skills matters of education with development of the vocational worldview and soft skills of a young doctor. We believe that one of the expedient integrate paradigm approaches that can help in this case are the methodological biopsychosocial approach to health and illness and the patient-centered approach to doctor's daily duties. These approaches set the framework for the formation of personalized axiological attitudes towards the patients. It should enter the core of the educational content that helps to connect the typical clinical aspects of a physician's work to patient education and health-oriented lifestyle education.

Vocational reflection is seen as an effective tool that helps a young doctor to expand beyond conventional perception of one's duties. Thoughts, insights, changes in the axiological system that a resident physician can get through analyzing one's experience, are targeted at the development of the humanistic personal culture of an aspiring physician.

\section{Conclusion}

Pedagogical components of daily job activities of a physician are aimed at forming a health-oriented lifestyle and patient education. These include a complex interpersonal interaction, intended to solve educational problems of retaining patient's health and 
sustaining medical treatment process and thus allowing to increase its efficiency. The pedagogical position of a physician is an integral characteristic of the personality of a specialist that should be formed and developed throughout continuous medical education. The pedagogical position of a doctor is part of overall vocational position. It allows to plan and fulfill health-oriented educational activities. The structure of a pedagogical position of a doctor, includes the following components: axiological component (job values and personal values), reflexive component, motivation, personal traits. These components altogether contribute to doctor's effective patient education knowledges, and skills. The ability to form the majority of these components within the Pedagogy course for resident physicians has been successfully implemented and confirmed. However, the deep-rooted physician's personality traits are unlikely to be changed in a short time frame.

\section{References}

1. Therapeutic patient education. Continuing education programmes for health care providers in the field of prevention of chronic disease. Report of a WHO Working Group. (1998)

2. Constitution of the World Health Organization. Basic Documents. Forty-fifth edition, Supplement. (2006)

3. Federal state educational standard of higher education (level of training of highly qualified personnel): Order of the Ministry of Education and Science of Russia dated 25.08.2014 No. 1085 "On approval of the federal state educational standard of higher education in the specialty Nephrology (Level of training of highly qualified personnel) (Registered with the Ministry of Justice of Russia 28.10 .2014 No. 34482)

4. A. Veal, The concept of lifestyle: a Review. Leisure studies, 12(4), 233-252 (1993)

5. D.D. Farhud, Impact of lifestyle on health Iran J Public Health, 44(11), 1442-1444 (2015).

6. M. Apostu, New Points of View on Concept of Health and Lifestyle. Procedia - Social and Behavioral Sciences, 92, 50-54 (2013).

7. M.P. O'Donnel, Definition of health promotion 2:0 embracing passion, enhancing motivation, recognizing dynamic balance, and creating opportunities. Am J Health Promot, 24(1) (2009).

8. A.K. Adams, O. Receveur, M.P. Mundt, G. Paradis A.C. Macaulay, Healthy Lifestyle Indicators in Children (Grades 4 to 6) from the Kahnawake Schools Diabetes Prevention Project // Canadian Journal of Diabetes, 29(4), 403-409 (2005)

9. Jerre Mae Tamanal, Cheong Hoon Kim, Promoting Healthy Lifestyle in High School students: Determination of the Lifestyle Status through the Healthy Lifestyle Screen (HLS) Assessment // J Lifestyle Med, 10(1), 30-43 (2020).

10. A.K. Wehling Weepie, A.M. McCarthy, A healthy lifestyle program: promoting child health in schools // j Sch Nurs. 18(6). 322-328. (2002).

11. D.A. Dudley, W.G. Cotton, R.L. Peralta, Teaching approaches and strategies that promote healthy eating in primary school children: a systematic review and metaanalysis // Int. J. Behavioral Nutrition and Physical Activity. 12, 28. https://doi.org/10.1186/s12966-015-0182-8 (2015).

12. N. Chau, A. Bhattacharjee, B.M. Kumar, Relationship between job, lifestyle, age and occupational injuries. Occupational Medicine, 59 (2), 114-119 (2019) 
13. S.A. Murphy, G.E. Bond, R.D. Beaton, J. Murphy, L.S. Johnson, Lifestyle practices and Occupational stressors as predictors of Health Outcomes in Urban Firefighters Int J. Stress Manag, 9(4) (2002)

14. J.J. Muros, F.S. Perez, F.Z. Ortega, V.M. Gamez Sanches, E. Knox, The association between healthy lifestyle behaviours and health-related quality of life among adolscents // J Pediatr (Rio J), 93(4), 406-412. (2017)

15. Chun-Han Lo, H. Khalili, Mingyang Song, P. Lochhead, K.E. Burke, J.M. Richter, E.L. Giavonucci, A.T. Chan, A.N. Ananthakrishnan, Healthy Lifestyle is associated with reduced mortality in patients with inflammatory Bowel Diseases // Clin Gastroenterol Hepatol. 19(1), 87-95 (2021)

16. S.A. Claas, D.K. Arnett, The role of Healthy Lifestyle in the Primordial Prevention of Cardiovascular Disease / // Cur. Cardiol. Rep. 18(6), 56 (2016)

17. Yanping Li, An Pan, Dong D Wang, Xiaoran Liu, Klodian Dhana, O.H. Franco, S. Kaptoge, E. Di Angelantonio, M. Stamfer, W.C. Willet, Frank B Hu, Impact of Healthy Lifestyle Factors on Life Expectancies in the US Population, Circulation 138(4), 345-355 (2018)

18. How to use ICF. A practical manual for International Classification of Functioning, Disability and Health (2013)

19. E.A. Vatskel, Specificity of the doctor's speech influence on the patient in the process of implementing pedagogical educational activities, Izvestiya RAE, 3, 88-95 (2018)

20. E.U. Vasilieva, T,V, Tagaeva, Model of pedagogical competence of a doctor in Proceedings of Conference Modern directions of theoretical and applied researches, March 17-19, 2015 Russia (2015)

21. S.N. Simaeva, S.I. Kulikov, Pedagogical competence of the future doctor: experience of using the technique of adult patients Bulletin of I. Kant BSU, 47-53 (2011).

22. E.U. Vasilyeva Assessment of readiness of medical university graduates for psychological and pedagogical work with a patient Ecology of Education and Science, 9, 38-43 (2015).

23. E.A. Vatskel, N.V. Krasilnikova, Formation of a professional pedagogical position of a doctor in the system of continuous medical education Yaroslavl Pedagogical Bulletin, 2, 128-132, (2017)

24. A.A. Bogatyrev, N.P. Vanchakova, A.P. Chernyavskaya, N.V, Krasilnikova, E.A. Vatskel. A.A. Babina, Development of a vocational and pedagogic position reflection of a doctor as part of continuing medical education program, in SHS Web Conf, Proceedings of the International Conference "Technological Educational Vision" (TEDUVIS 2020), 97, December 4, 2020, Prague, Chech Republic (2021).

25. A. Mehrabian, N. Epstein, A measure of emotional empathy. Journal of Personality, 40, 525-543 (1972)

26. A. V. Karpov, Reflexivity as a psychological atribute and methods of its diagnostics, Psychological journal, 24, 5, 45-57 (2003). 